\title{
Rate of transmission: A major determinant of the cost of clinical mastitis
}

\author{
P. M. Down, ${ }^{1}$ M. J. Green, and C. D. Hudson \\ School of Veterinary Medicine and Science, University of Nottingham, Sutton Bonington Campus, Sutton Bonington, LE12 5RD, United Kingdom
}

\begin{abstract}
The aim of this research was to use probabilistic sensitivity analysis to evaluate the relative importance of different components of a model designed to estimate the cost of clinical mastitis $(\mathrm{CM})$. A particular focus was placed on the importance of pathogen transmission relative to other factors, such as milk price or treatment costs. A stochastic Monte Carlo model was developed to simulate a case of CM at the cow level and to calculate the associated costs for 5 defined treatment protocols. The 5 treatment protocols modeled were $3 \mathrm{~d}$ of antibiotic intramammary treatment, $5 \mathrm{~d}$ of antibiotic intramammary treatment, $3 \mathrm{~d}$ of intramammary and systemic antibiotic treatment, $3 \mathrm{~d}$ of intramammary and systemic antibiotic treatment plus $1 \mathrm{~d}$ of nonsteroidal antiinflammatory drug treatment, and $5 \mathrm{~d}$ of intramammary and systemic antibiotic treatment. Uniform distributions were used throughout the model to enable investigation of the cost of CM over a spectrum of clinically realistic scenarios without specifying which scenario was more or less likely. A risk of transmission parameter distribution, based on literature values, was included to model the effect of pathogen transmission to uninfected cows, from cows that remained subclinically infected after treatment for CM. Spearman rank correlation coefficients were used to evaluate the relationships between model input values and the estimated cost of CM. Linear regression models were used to explore the effect that changes to specific independent variables had on the cost of CM. Risk of transmission was found to have the strongest association with the cost of $\mathrm{CM}$, followed by bacteriological cure rate, cost of culling, and yield loss. Other factors such as milk price, cost of labor, and cost of medicines were of minimal influence in comparison. The cost of CM was similar for all 5 treatment protocols. The results from this study suggest that, when seeking to minimize the economic impact of CM in dairy herds, great emphasis should be placed on the reduction of pathogen transmission from cows with CM to uninfected cows.
\end{abstract}

\footnotetext{
Received December 11, 2012.

Accepted June 22, 2013.

${ }^{1}$ Corresponding author: svxpd1@nottingham.ac.uk
}

Key words: mastitis, treatment, probabilistic sensitivity analysis, transmission

\section{INTRODUCTION}

Mastitis remains one of the most common diseases of dairy cows and represents a large economic loss to the industry as well as a considerable welfare issue to the cows affected (Bradley, 2002; Halasa et al., 2007). Despite being an infectious disease, concentration is often focused on the individual animal with respect to treatment, cost, and management. The risk posed to the rest of the herd from infected individuals and the potential impact of disease transmission on the cost of a case of clinical mastitis (CM) is often overlooked.

The cost of CM is made up of direct costs (e.g., discarded milk, cost of medicines, and labor) and indirect costs (e.g., loss of future production and increased culling) and varies considerably between farms (Huijps et al., 2008). Although the direct costs are more apparent to the producer, they are reported to comprise only a small proportion of the overall cost of CM compared with the less-obvious indirect costs (Kossaibati and Esslemont, 2000; Huijps et al., 2008). Several studies have taken all of the direct and indirect costs into account and have produced average figures of $\$ 168$ (Bar et al., 2008), \$254 (Huijps et al., 2008), \$266 (Kossaibati and Esslemont, 2000), and \$518 (Hagnestam-Nielsen and Ostergaard, 2009) for the cost of a case of CM. Although this information is useful, such average figures are difficult to interpret for an individual producer unless they happen to have the average farm. Although some recent studies have investigated the impact of transmission on the overall cost of $\mathrm{CM}$ at herd level (Halasa et al., 2009; van den Borne et al., 2010; Halasa, 2012), most studies have not evaluated the impact that within-herd transmission may have on the cost of CM at the cow level, nor how important this may be relative to the other factors that make up the overall cost of a case of CM.

A technique now widely adopted by the human healthcare sector for analysis of the cost-effectiveness of new and existing treatments is probabilistic sensitivity analysis (PSA; Briggs et al., 2002; Brown et al., 2006). Indeed, the National Institute for Clinical Excellence 
(NICE; London, UK) now requires all cost-effectiveness analyses submitted to the institute to use PSA (Claxton et al., 2005). The main feature of this technique is that all input parameters in a cost-effectiveness model are specified as full probability distributions (probabilistic), rather than point estimates (deterministic), to represent the uncertainty surrounding their values. This parameter uncertainty can then be propagated through the cost-effectiveness model so that imprecision in model outputs is transparent (Briggs et al., 2002). For example, rather than using a point estimate for the probability of clinical cure after the treatment of $\mathrm{CM}$ of, say, $60 \%$, we might choose a probability distribution covering the range 40 to $80 \%$ instead, accepting that we don't know the precise figure, but being fairly confident that it lies somewhere within this range. The relative importance of different model parameter values on the outcome of interest can then be evaluated irrespective of model complexity. This form of analysis has widespread acceptance within the human healthcare sector, but the authors could find only 1 example of its use in the veterinary literature (Detilleux, 2004).

The purpose of this research was to use PSA to evaluate the relative importance of different components of a model designed to estimate the cost of CM. The model included the potential for pathogen transmission between cows and was an extension of a previously described model structure (Steeneveld et al., 2011). A particular aim was to assess the importance of the rate of transmission relative to other factors, such as milk price or the cost of therapeutic agents.

\section{MATERIALS AND METHODS}

\section{Model Structure}

A stochastic Monte Carlo model was developed using WinBUGS 1.4.3 software (Lunn et al., 2000). This was used to simulate an initial case of CM (CM1) at the cow level and to calculate the associated costs simultaneously for 5 treatment protocols as defined by Steeneveld et al. (2011). The 5 protocols used were 3 $\mathrm{d}$ of antibiotic intramammary treatment (treatment 1), $5 \mathrm{~d}$ of antibiotic intramammary treatment (treatment 2), $3 \mathrm{~d}$ of intramammary and systemic antibiotic treatment (treatment 3), 3 d of intramammary and systemic antibiotic treatment plus $1 \mathrm{~d}$ of nonsteroidal antiinflammatory drug treatment (treatment 4), and $5 \mathrm{~d}$ of intramammary and systemic antibiotic treatment (treatment 5). The initial probability that the cow was cured bacteriologically was defined by a probability distribution based on the maximal cure rates given by Steeneveld et al. (2011), but rather than being pathogen specific (e.g., Staphylococcus aureus, Strepto- coccus dysgalactiae/uberis, or Escherichia coli), a single distribution was used providing coverage of cure rates encompassing those for all of the pathogens modeled by Steeneveld et al. (2011). For example, for treatment 1 (3 d of intramammary treatment), the bacteriological cure rates given ranged from 0.80 for $E$. coli infections down to 0.40 for Staph. aureus infections, so the uniform distribution 0.40 to 0.80 was used for all treatment-1 cases. After an initial treatment, 3 outcomes were possible: complete cure (bacteriological plus clinical cure), clinical cure (with no bacteriological cure), or no cure (no clinical and no bacteriological cure), with probabilities based upon Steeneveld et al. (2011; Table 1). The probability that a case was cured bacteriologically was assumed to be further influenced by whether the cow was systemically ill, the SCC at the time of treatment, the DIM at the time of treatment, parity, and whether it was a repeat case or not (Steeneveld et al., 2011; Table 1). The cows that failed to cure bacteriologically were deemed to have an $80 \%$ chance of curing clinically (Steeneveld et al., 2011).

The model structure was adapted from the model described by Steeneveld et al. (2011; Figure 1), which models the sequelae following a case of $\mathrm{CM}$ within a single lactation, with the addition of a risk of transmission from cows that cured clinically but not bacteriologically. Cases that completely cured could either go on to finish the lactation or be culled within the remainder of the lactation. The probability of being culled was increased if the cow was systemically ill at the time of treatment. The cows that cured clinically but not bacteriologically could go on to finish the current lactation, be culled, or have a clinical recurrence of the original case (CM2). If a cow did not cure, it would receive a repeat course of the initial treatment protocol, resulting in the same 3 possible outcomes as previously outlined. Cows that failed to cure after a repeated course could either die or have the quarter dried off. If a quarter was dried off, the cow could then go on to finish the lactation at a reduced level of milk production, or be culled (Table 2). The same sequence of events was modeled for CM2, but after CM3 the options became narrower. The cows that cured completely after CM3 could either end the lactation or be culled. The clinical (but not bacteriological) cures and the "no cures" were culled as was the case in the model described by Steeneveld et al. (2011). The probabilities of a cow being culled varied according to whether the case was a first, second, or third case. The distributions used in the model are shown in Tables 1 and 2. Following each treatment for $\mathrm{CM}$, the probability of a cow curing bacteriologically was selected from the specified distribution and of those cows that failed to cure, $80 \%$ were assumed to cure clinically but not bacteriologi- 
cally as described by Steeneveld et al. (2011) and the remaining cows were assumed to fail to cure.

A risk of transmission was included from cows that cured clinically but not bacteriologically (those that did not cure clinically received another treatment and were deemed to be not at risk of transmission at this point). The probability that a cow transmitted infection to a herd mate (Table 2) was taken from van den Borne et al. (2010), who reported estimated transmission rates over a 14-d period for infections caused by Staph. aureus, Strep. uberis/dysgalactiae and E. coli. A uniform distribution was specified [range 0.002 to 0.25, encompassing the estimates of van den Borne et al. (2010)], from which a value was selected at random at each iteration and used for each period of risk thereafter. The total period of transmission risk modeled was limited to $12 \mathrm{wk}$, split into 14-d intervals for CM1 and CM2. Therefore, the risk of transmission had a wide distribution to reflect and encompass all types of pathogens and strains. Thus, using 1 distribution, we could evaluate differences between a very-low-transmission pathogen and a very-high-transmission pathogen.

The susceptible population was taken as the whole herd (99 cows) at the start of the transmission period and was reduced according to the number of cows that became infected after each 14-d period during the subsequent $12 \mathrm{wk}$. Cow parities and stage of lactation of the susceptible population were not modeled separately; thus, for simplicity, all susceptible cows we assumed to have an equal probability of acquiring an infection. All cows that were infected at the end of the previous 14-d period were eligible to transmit infection during the next 14-d period according to the defined probability distribution (Table 2). For example, if the cow treated at CM1 remained subclinically infected after treatment, it could transmit the infection to another cow in the herd during the following 14-d period. At the start of the subsequent 14-d period, 2 infectious cows could now be able to transmit infection to another 2 cows during the next 14-d period. If 3 cows had become infected in addition to the original case, then the susceptible population would be reduced to 96 cows. The total number of infections accrued from CM1 and CM2 were combined and the costs of subsequent cases of CM were estimated by multiplying the cost from the original case (CM1) by the number of extra cases of CM caused by transmission of the original infection (thus assuming the same milk price, culling values, and so on, as for the initial case). A total cost of CM was derived by adding the costs from the original and secondary cases, following transmission. For example, if the cost of a case of $\mathrm{CM}$ was calculated to be $\$ 200$ (excluding transmission) but the cow infected 2 herd mates, then the total cost 


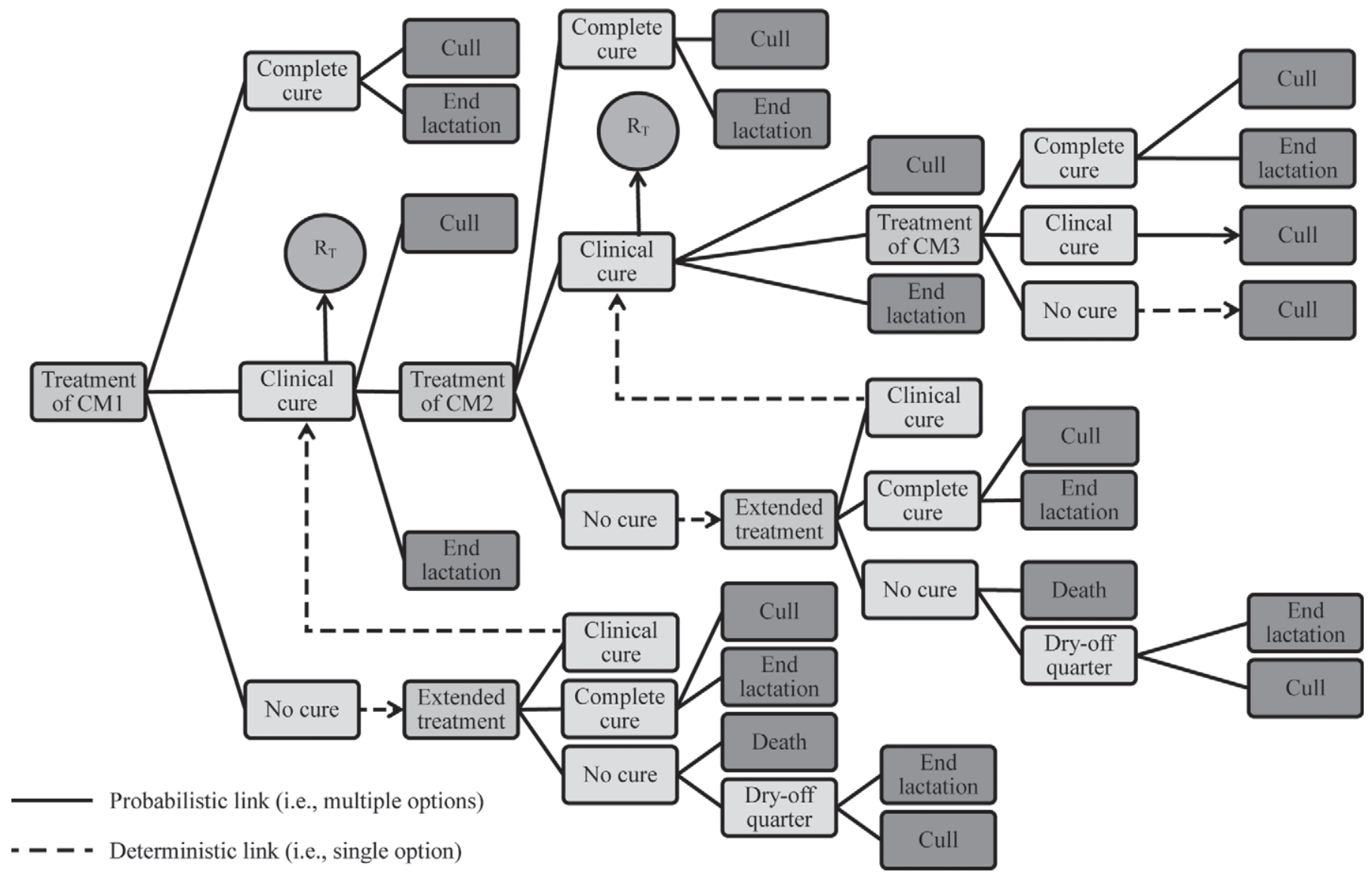

Figure 1. Schematic representation of the treatment model. Complete cure $=$ bacteriological and clinical cure; clinical cure $=$ no bacteriological cure but clinical cure; no cure = no bacteriological or clinical cure; cull = culled sometime within the remainder of the current lactation; extended treatment $=$ a repeat of the same treatment that the case received initially; $\mathrm{R}_{\mathrm{T}}=$ risk of transmission; CM1 $=$ initial case of clinical mastitis; CM2 = first clinical flare-up; CM3 = second clinical flare-up.

(including transmission) would be calculated as $\$ 600$ $(\$ 200 \times 3)$.

\section{Model Input Parameters}

The model was parameterized (i.e., the model inputs selected) with distributions taken from the existing literature and from current commercial data, and where no other information was available, on transparent assumptions made by the dairy health group, University of Nottingham (Sutton Bonington, UK; Tables 1 and 2 ). The purpose was to enable exploration of the relationship between each model parameter and the overall cost-benefit of each treatment protocol over a wide range of possible scenarios. Although not a requirement of PSA, uniform distributions were used throughout the model to enable evaluation of the cost of CM over a spectrum of different scenarios without specifying which scenarios were more or less likely, thereby minimizing assumptions. This was not intended to represent the true distribution of the input parameters (which are generally unknown), but simply to allow investigation over the whole of a realistic range of equally likely parameter values and thus treatment scenarios. After a large number of model iterations (4,000 per treatment protocol), all combinations of treatment scenarios and other input parameters were effectively investigated so that dependencies could be evaluated.

Where possible, distribution ranges were based on values from current literature. Where a point estimate was identified in the literature, a uniform distribution centered on that point was used, to allow sensitivity analysis of realistic values around this point estimate. For example, the increase in probability of a cow being culled within the remainder of lactation when systemically ill was estimated to be 0.10 (Steeneveld et al., 2011). In our model, a uniform distribution of 0.05 to 0.15 was used to evaluate this parameter over an enlarged but specified range. The distributions used for input parameters are shown in Tables 1 and 2, along 
Table 2. Probability distributions applicable to all 5 antimicrobial clinical mastitis (CM) treatment protocols

\begin{tabular}{|c|c|c|}
\hline Input parameter & $\begin{array}{l}\text { Lower and upper } \\
\text { limits of uniform } \\
\text { distribution }\end{array}$ & Source \\
\hline Change in the probability of bacteriological cure ${ }^{1}$ & & Based on Steeneveld et al. (2011) \\
\hline Parity $\geq 2$ & $-0.15,-0.05$ & \\
\hline $\mathrm{DIM} \geq \overline{6} 0$ & $-0.15,-0.05$ & \\
\hline Cow is systemically ill & $-0.25,-0.15$ & \\
\hline SCC 200,000 to 500,000 cells $/ \mathrm{mL}$ at most recent recording & $-0.15,-0.05$ & \\
\hline $\mathrm{SCC}>500,000$ cells $/ \mathrm{mL}$ at most recent recording & $-0.25,-0.15$ & \\
\hline Repeated case (>first case in current lactation) & $-0.25,-0.15$ & \\
\hline Probability of being culled for bacteriologically noncured cases & & Based on Steeneveld et al. (2011) \\
\hline Initial case & $0,0.32$ & \\
\hline Following first flare-up (CM2) & $0.04,0.36$ & \\
\hline Probability of being culled for completely cured cases & & Based on Steeneveld et al. (2011) \\
\hline Initial case & $0.04,0.06$ & \\
\hline Following first flare-up (CM2) & $0.10,0.20$ & \\
\hline Following second flare-up (CM3) & $0.20,0.30$ & \\
\hline Probability of death for nonclinically cured cases & $0.04,0.06$ & Based on Steeneveld et al. (2011) \\
\hline Probability of drying-off quarter for nonclinically cured cases & $0.94,0.96$ & Based on Steeneveld et al. (2011) \\
\hline Probability of being culled for cows with dried-off quarters & $0.27,0.39$ & Based on Steeneveld et al. (2011) \\
\hline Increase in all culling probabilities when cow is systemically ill & $0.05,0.15$ & Based on Steeneveld et al. (2011) \\
\hline Probability of clinical flare-up for bacteriologically noncured cases & $0.05,0.12$ & Based on Steeneveld et al. (2011) \\
\hline Probability of transmission after CM1 and CM2 & $0.002,0.25$ & van den Borne et al. (2010) \\
\hline Proportional yield loss & & Based on Steeneveld et al. (2011) \\
\hline Case in first or second month of lactation & $0.07,0.09$ & \\
\hline Case between mo 3 and 6 & $0.03,0.08$ & \\
\hline Case after mo 6 & $0,0.04$ & \\
\hline Parity $\geq 2$ & $0,0.02$ & \\
\hline 305-d yield $(\mathrm{kg})$ & $7,000,10,000$ & Authors' expertise \\
\hline Daily milk discard $(\mathrm{kg})$ & $5.00,50.00$ & Authors' expertise \\
\hline Value of discarded milk ( $\$ / \mathrm{kg})$ & $0.35,0.41$ & DairyCo (2012a) \\
\hline Cost of milk production $(\$ / \mathrm{kg})$ & $0.05,0.15$ & Based on Huijps et al. (2008) \\
\hline Cost of labor $(\$ / \mathrm{h})$ & $1.52,24.07$ & Based on Huijps et al. (2008) \\
\hline Cost of cull $(\$)$ & $182,1,092$ & Based on Huijps et al. (2008) and Kossaibati and Esslemont (2000) \\
\hline Cost of death $(\$)$ & $1,820,3,033$ & DairyCo $(2012 \mathrm{~b})$ \\
\hline
\end{tabular}


with the source or basis for the choice of each distribution.

Economic parameter distributions included the cost of drugs (Table 1), labor, milk withdrawal and loss of milk production, culling, and death (Table 2). The original calculations were made in British pounds $(£)$ and converted to US dollars (\$) using the exchange rate of $1.5170 \$ / £$ (http://www.xe.com/currency converter/; accessed March 5, 2013). The cost of labor is subject to large variation quoted in the literature. For this reason, a wide distribution was assigned to the hourly cost of labor, with the upper limit taken from Huijps et al. (2008). The total time taken to treat each case of CM was assigned a distribution centered on the figures given by Steeneveld et al. (2011), surrounded by an additional variation of $\pm 10 \mathrm{~min}$. The total cost of labor was the product of the hourly rate and the total treatment time.

The length of milk withdrawal after CM was defined by a distribution based on the commonly used medicines in the United Kingdom and the amount of milk being discarded each day was taken from a plausible milk yield distribution (Table 1). The distribution defined for milk price was taken from DairyCo (2012a) and based on the average UK milk price over the last 12 mo (range: lowest price to highest price). The cost of milk production was based on Huijps et al. (2008) and assigned a uniform distribution to reflect the variability in the figure (Table 2).

The calculation of total yield loss following a case of CM was based on the herd 305-d yield, the parity of the animal, and the stage of lactation in which the infection occurred (Table 2). The distributions governing the percentage of total loss in 305-d milk yield were based on Hagnestam et al. (2007). The proportion of cases occurring at each stage postpartum and the proportion of cases affecting multiparous cows versus primiparous cows was governed by distributions based on Steeneveld et al. (2011; Table 2). The cost associated with the total loss in milk yield was calculated according to the total loss in earnings (i.e., the quantity of milk multiplied by the milk price) minus the savings made in feed costs (i.e., the quantity of milk loss multiplied by the cost of production). All distributions are provided in Table 2.

The cost of culling a cow within the remainder of the current lactation was taken from a uniform distribution based on Huijps et al. (2008) and Kossaibati and Esslemont (2000), which included the slaughter value and replacement costs, with an appropriate range added to reflect the variability of this parameter (Table 2). The cost of the death of an individual was based on current UK average sales prices for freshly calved cows and heifers (DairyCo, 2012b), which would be required to replace the dead cow in addition to the cost of carcass disposal (Table 2).

\section{Model Simulation}

The model was used to simulate 4,000 cases of CM1 for each treatment protocol. At each iteration, all model input parameter values for that iteration were stored along with the calculated cost of a CM1 case; this data was then used for analysis.

At each model iteration, a value for each input parameter was drawn from the probability distribution for that input parameter, independent of other parameter values selected, and the model used to calculate a cost of CM based on those input values. At the next iteration, a new set of parameter values were selected at random and used to calculate a cost of CM. This process was repeated 4,000 times for each of the 5 treatment protocols and the impact of each parameter on the cost of CM was evaluated.

\section{Data Analysis}

Spearman rank correlation coefficients were calculated to explore the univariate associations between model input parameters and the cost of CM (Table 3). The strength of the relationship was evaluated using the Spearman rank rho $(\rho)$ value.

Conventional first-order multiple linear regression models were used to explore the relationships between model inputs (Tables 1 and 2) and the cost of CM for each of the treatment protocols (one model was constructed for each treatment protocol). A natural logarithmic transformation was required for the outcome variable (cost of $\mathrm{CM}$ ) to give normality and homoscedasticity of the residuals. Model fit was assessed using a visual assessment of residuals and a quantile-quantile plot to evaluate normality. The influence of any outlying residuals was assessed using the Cook's D value. Predictor variables were selected by backward stepwise selection and variable coefficients that were significantly different from zero $(P<0.05)$ were retained in the final model. All analysis was performed in $\mathrm{R}$ version 2.15 .0 software (R Development Core Team, 2012).

The relative importance of the independent variables (model input parameters) on the cost of CM was assessed for each of the 5 treatment protocols by removing the variable from the model and observing the difference in the resulting coefficient of determination value. This difference was then expressed as a proportion of the coefficient of determination value of the complete model.

The final regression models were used to make predictions based on different cow and farm scenarios and 
Table 3. Spearman rank correlation coefficients measuring the statistical dependence between the main specified variables and the total cost of clinical mastitis

\begin{tabular}{|c|c|c|c|c|c|}
\hline \multirow[b]{2}{*}{ Item } & \multicolumn{5}{|c|}{ Antimicrobial treatment regimen } \\
\hline & Treatment $1^{1}$ & Treatment $2^{2}$ & Treatment $3^{3}$ & Treatment $4^{4}$ & Treatment $5^{5}$ \\
\hline Transmission & 0.70 & 0.68 & 0.71 & 0.70 & 0.64 \\
\hline Bacteriological cure rate 6 & -0.24 & -0.10 & -0.07 & -0.13 & -0.09 \\
\hline Cost of cull & 0.23 & 0.24 & 0.24 & 0.24 & 0.25 \\
\hline Total yield loss & 0.23 & 0.23 & 0.22 & 0.22 & 0.23 \\
\hline Not systemically ill & -0.23 & -0.25 & -0.25 & -0.25 & -0.27 \\
\hline Heifer & -0.15 & -0.16 & -0.16 & -0.17 & -0.17 \\
\hline Not a repeat case & -0.12 & -0.14 & -0.13 & -0.14 & -0.15 \\
\hline Milk price & 0.10 & 0.11 & 0.11 & 0.11 & 0.11 \\
\hline $\mathrm{SCC}>500,000$ cells $/ \mathrm{mL}^{7}$ & 0.10 & 0.09 & 0.09 & 0.08 & 0.09 \\
\hline Cost of milk production & -0.10 & -0.10 & -0.10 & -0.11 & -0.11 \\
\hline Less than $60 \mathrm{DIM}^{8}$ & -0.09 & -0.10 & -0.10 & -0.11 & -0.11 \\
\hline Milk withdrawal $^{9}$ & 0.09 & 0.07 & 0.07 & 0.12 & 0.07 \\
\hline Cost of labor & 0.02 & 0.04 & 0.02 & 0.02 & 0.04 \\
\hline Cost of drugs & 0.02 & 0.00 & 0.02 & 0.00 & 0.01 \\
\hline \multicolumn{6}{|c|}{${ }^{1}$ Three days of antibiotic intramammary treatment. } \\
\hline \multicolumn{6}{|c|}{$\begin{array}{l}\text { Three days of antibiotic intramammary treatment. } \\
{ }^{2} \text { Five days of antibiotic intramammary treatment. }\end{array}$} \\
\hline \multicolumn{6}{|c|}{${ }^{3}$ Three days of intramammary and systemic antibiotic treatment. } \\
\hline \multicolumn{6}{|c|}{$\begin{array}{l}{ }^{4} \text { Three days of intramammary and systemic antibiotic treatment plus } 1 \mathrm{~d} \text { of nonsteroidal antiinflammatory } \\
\text { drug treatment. }\end{array}$} \\
\hline \multicolumn{6}{|c|}{${ }^{5}$ Five days of intramammary and systemic antibiotic treatment. } \\
\hline \multirow{2}{*}{\multicolumn{6}{|c|}{$\begin{array}{l}{ }^{6} \text { Baseline bacteriological cure rate before further influence of systemic illness, parity, DIM, SCC, and case } \\
\text { number. } \\
{ }^{7} \text { Somatic cell count at the time of clinical mastitis. }\end{array}$}} \\
\hline & & & & & \\
\hline \multicolumn{6}{|c|}{${ }^{8}$ Less than 60 DIM at the time of clinical mastitis case. } \\
\hline
\end{tabular}

to explore the predicted effect these would have on the overall cost of CM. This was undertaken by altering the value of each of the independent variables in the model in turn from their median value to the 97.5 th percentile while keeping all other variables constant at their median value and recording the resulting change in the model output (cost of CM) as a percentage. This was performed using Microsoft Excel 2010 software (Microsoft Corp., Redmond, WA).

\section{RESULTS}

\section{Data Analysis}

The Spearman rank correlation coefficients are presented in Table 3. The cost of CM was most closely associated with the risk of transmission of infection for all 5 treatment protocols. This was followed by the bacterial cure rate, the cost of a cull, total loss in yield, and the presence or absence of systemic illness.

The regression model fit was good for each of the 5 treatment protocols and outliers had no significant influence on the model output. The results of the regression analysis are illustrated in Figure 2. Transmission of infection had the greatest influence on the overall cost of $\mathrm{CM}$ for all 5 treatment protocols, and the number of cows infected as a result of CM1 ranged from 0 to 3 over the total period of risk (Table 4). This was followed by occurrence of systemic illness, cost of a cull and total yield loss during the remainder of the lactation. In total, 13 independent variables were retained in the final models. The relative importance of variables differed only slightly between the 5 treatment protocols; the general trends were similar throughout.

The most influential financial input was the cost of a cull, which accounted for around $10 \%$ of the variance in the total cost of CM, followed by the cost of milk production, milk price, and cost of labor. The cost of drugs was not found to be a significant predictor and was excluded from the final models. The relationship between the most important independent variables and the cost of CM are displayed in Figure 3.

\section{Scenarios}

The regression models were used to explore the effect that changes to specific independent variables had on the overall cost of $\mathrm{CM}$ and the results from treatment 1 are displayed in Figure 4. An increase in the rate of transmission from 0.13 to 0.25 new cases $/ 14 \mathrm{~d}$ would increase the predicted cost of CM by up to $60 \%$, whereas doubling the cost of labor from around $\$ 12.89$ 

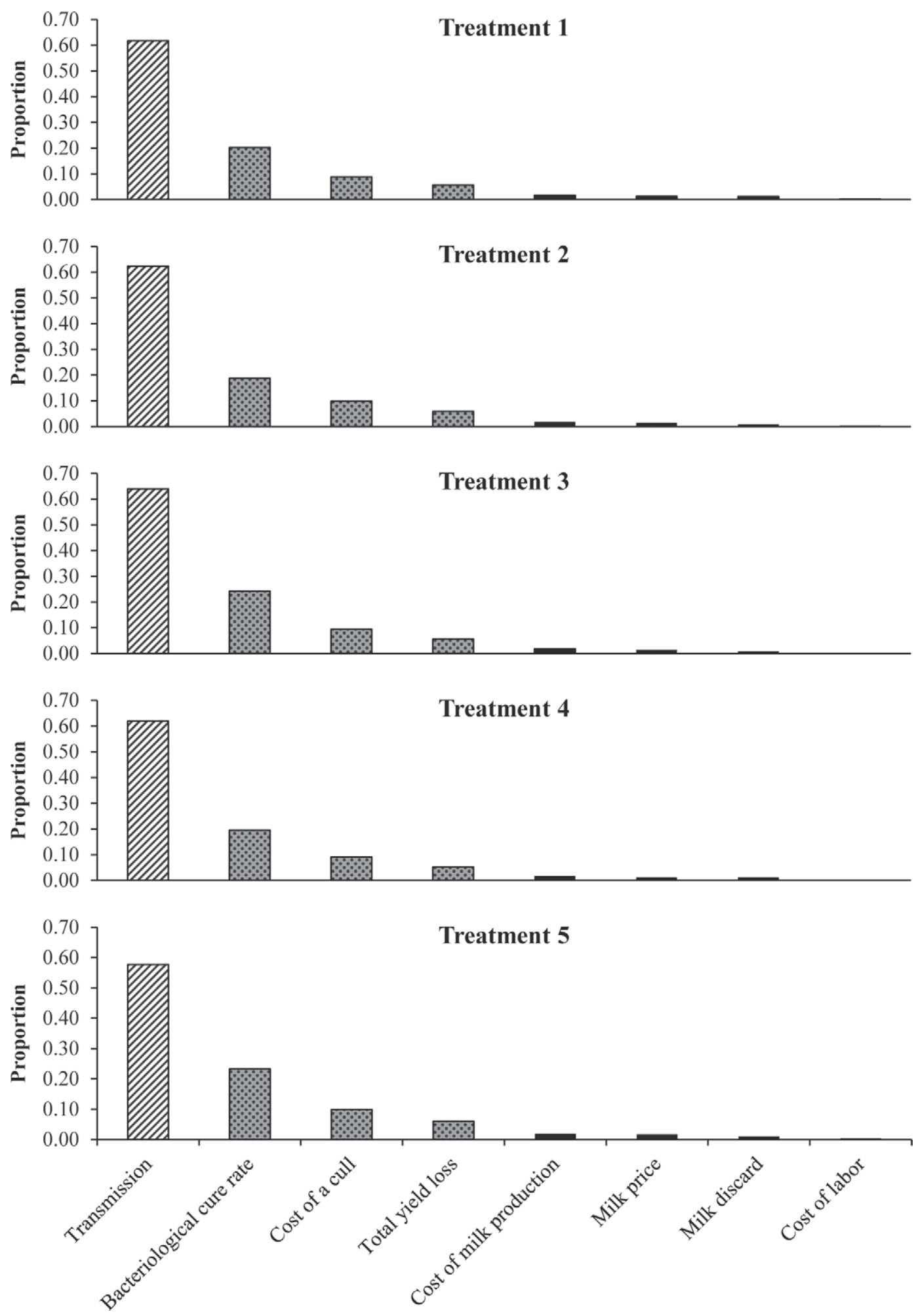

Figure 2. Bar charts depicting the proportion of variance in the total cost of clinical mastitis $(\mathrm{CM})$ accounted for by each variable in the regression model for each of the treatment protocols. Treatment $1=3 \mathrm{~d}$ of antibiotic intramammary treatment; treatment $2=5 \mathrm{~d}$ of antibiotic intramammary treatment; treatment $3=3 \mathrm{~d}$ of intramammary and systemic antibiotic treatment; treatment $4=3 \mathrm{~d}$ of intramammary and systemic antibiotic treatment plus $1 \mathrm{~d}$ of nonsteroidal antiinflammatory drug treatment; treatment $5=5 \mathrm{~d}$ of intramammary and systemic antibiotic treatment. Milk discard $=$ milk discarded during treatment. 
to $\$ 23.51 / \mathrm{h}$ would only be expected to increase the cost of mastitis by around 5\%. Systemic illness had a large effect on the total cost of CM (40\%), if present due to the depressing effect this had upon the probability of bacteriological cure. The cost of a cull had a moderate effect on the cost of CM, with an increase from $\$ 637$ to $\$ 1,065$ resulting in a 15 to $20 \%$ increase in the overall cost.

\section{DISCUSSION}

The results suggest that the risk of transmission of infection has the greatest influence on the cost of a case of $\mathrm{CM}$ and this appeared to be by a wide margin. Indeed, a relatively small increase in the rate of transmission was associated with a large increase in cost (Figure 4) and this is consistent with a study by Halasa (2012) that reported that the total annual net cost of IMI was highly sensitive to the transmission rate of Staph. aureus.

The potential for transmission of IMI between cows is well established (Barkema et al., 2009) and yet despite this, relatively few studies exist that seek to quantify this phenomenon (Lam et al., 1996; Zadoks et al., 2001, 2002). The transmission data from these studies has been used to inform some economic (Swinkels et al., 2005a,b; van den Borne et al., 2010) and epidemiological studies (Barlow et al., 2009), but these were all set in the context of treatment of subclinical mastitis. One study that did include transmission in a discrete-event model investigating the cost of pathogen-specific IMI in a herd of 100 dairy cows, found that the total net cost was most sensitive to the transmission rate parameter (Halasa et al., 2009). A limitation of previous research on pathogen-specific transmission rates is that the rate is likely to vary considerably between different strains of the same pathogen and the advantage of using PSA is that a single distribution could be used to encompass many different plausible rates (based on the literature) and the importance of this parameter could be investigated without the need to make assumptions as to how a particular pathogen may or may not behave. Therefore, the variation in the transmission rate parameter in this study effectively takes into account known variation in pathogen and strain of bacteria. Although the use of uniform distributions means that no assessment is made as to which scenario is more or less likely and, therefore, which transmission value is most common, their use does mean that the relative importance of the different transmission values affecting the cost of $\mathrm{CM}$ can be robustly assessed across a wide range of plausible situations.

In the model described in this study, cows that cured bacteriologically following treatment could go on to 

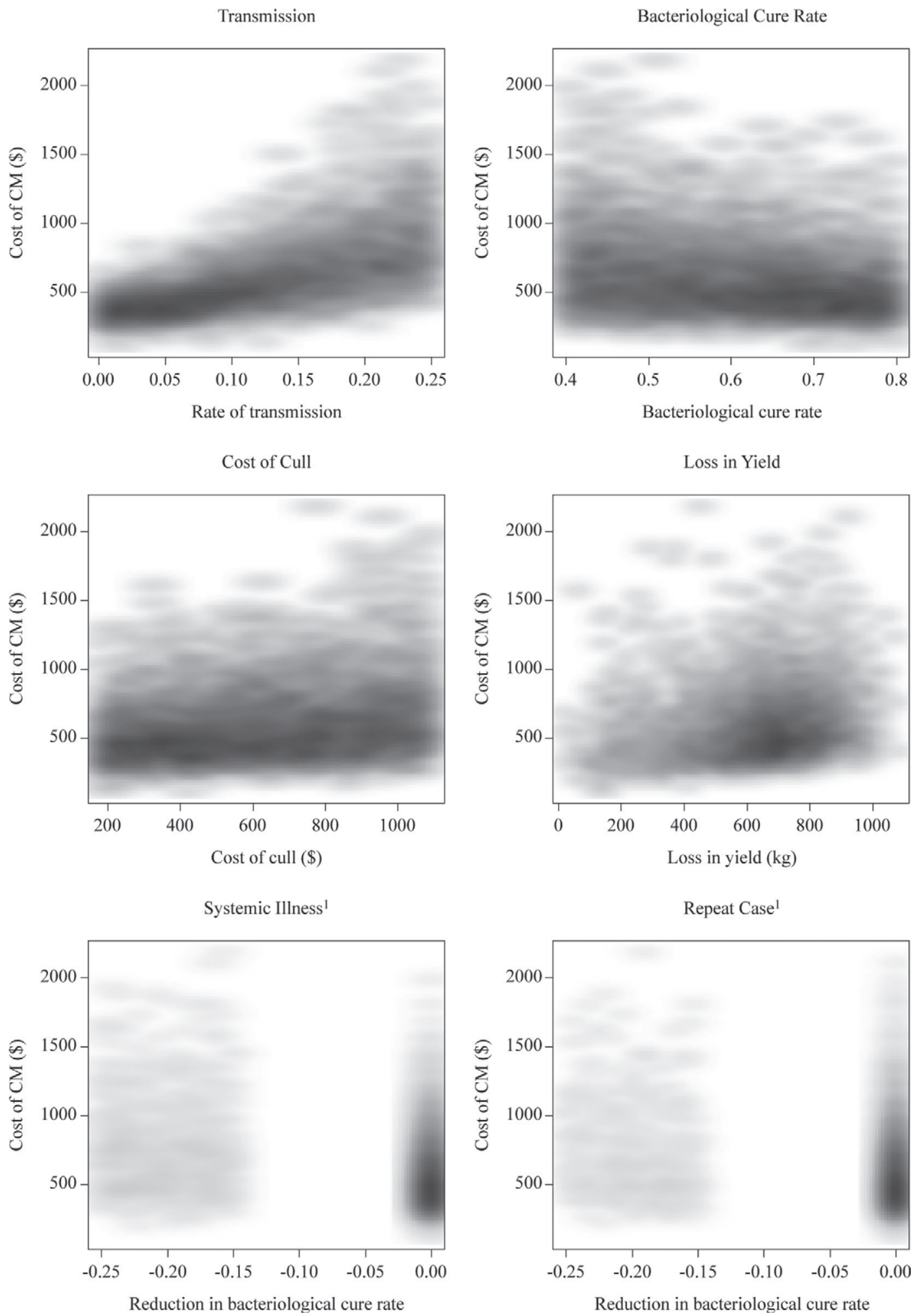

Figure 3. Series of high-density scatterplots [relatively darker shading means relatively greater point density (i.e., occurred more frequently)] demonstrating the relationship between a predictor variable and the total cost of clinical mastitis (CM) for treatment 1 (3 d of intramammary antibiotic). Transmission refers to the risk of cows becoming infected due to the original case over a 12-wk period. Bacteriological cure rate refers to the baseline bacteriological cure rate, without accounting for systemic illness, parity, DIM, SCC, or repeat case. ${ }^{1}$ Binary outcome; therefore, 2 possible outcomes exist. The cluster of data points on the left-hand side of the chart represent the cost of mastitis, given the presence of the predictor variable and the cluster of points on the right-hand side of the chart indicates the cost of mastitis, given the absence of the predictor variable. The $\mathrm{x}$-axis value represents the effect on the probability of bacteriological cure. 
Treatment 1

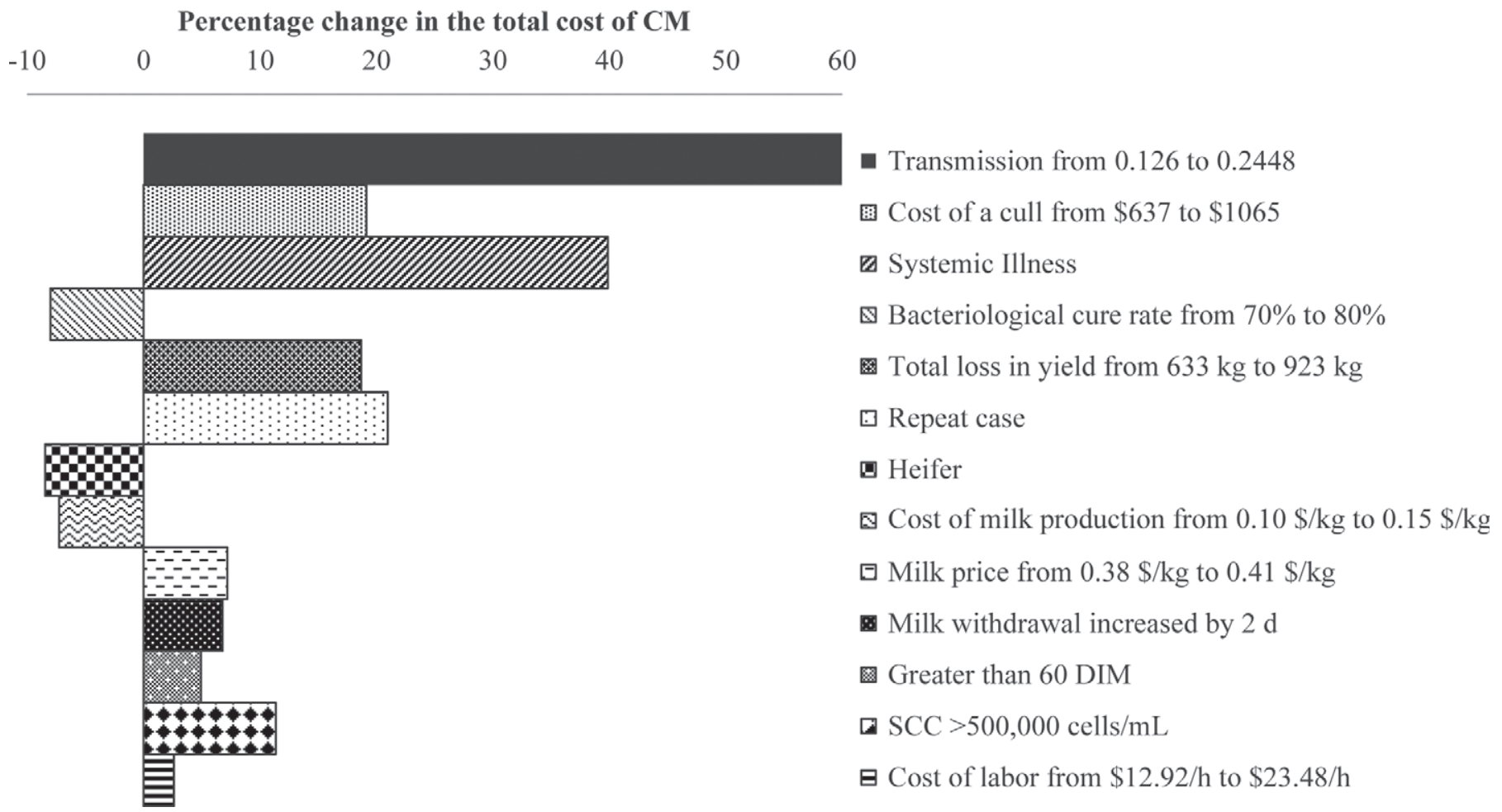

Figure 4. Tornado plot to demonstrate the predicted effect of a change in the predictor variable from the 50th to the 97.5th percentile on the total cost of clinical mastitis (CM) when all of the others remain constant in the regression model. The results for treatment 1 only are displayed, as results were similar for all 5 treatment protocols. Treatment $1=3 \mathrm{~d}$ of intramammary antibiotic treatment. Transmission refers to the risk of transmission over a $14-\mathrm{d}$ period.

either finish the lactation or be culled and at no point could they transmit infection to other cows. Cows that remained subclinically infected could either end the lactation, be culled, or experience a repeat case of CM and during this time they were considered eligible to transmit infection, whichever route they followed. Although this may represent a simplification of the biological reality, it is probably these subclinically infected cows that represent the major reservoir of contagious pathogens and the way in which those cows are managed could have a significant effect on the degree of between-cow transmission and hence the cost of mastitis.

Transmission of contagious mastitis pathogens mainly occurs during milking (Fox and Gay, 1993) and measures aimed at reducing transmission therefore tend to focus on the milking process, the management of the cows at milking, and the milking machine itself. A recent systematic review of the effect of udder health management practices on herd SCC highlighted the importance of wearing gloves while milking, the use of (well-adjusted) automatic cluster removal, application of postmilking teat disinfection, milking cows with
CM or a high SCC last, and the annual inspection of the milking machine (Dufour et al., 2011). Although such studies measuring association are not evidence of causality, they do highlight practices that are likely to help minimize the transmission of IMI and appear to be relatively well adopted by dairy farmers (Rodrigues et al., 2005; Olde Riekerink et al., 2010). The segregation of infected cows represents a challenge for many producers, both logistically and diagnostically, because creating an additional group may add to space and time pressures and a certain amount of expenditure and effort will be required to diagnose infected cows. Despite this, it would seem logical that keeping infectious cows separate to susceptible individuals should reduce spread and evidence exists to support this in the literature (Wilson et al., 1995; Middleton et al., 2001; Zecconi et al., 2003). A possible alternative to segregation is backflushing the milking unit to prevent uninfected cows from being exposed to contaminated milking units from infectious cows (Keefe, 2012) and some evidence exists of its efficacy (Hogan et al., 1984; Smith et al., 1985). Although this may represent a significant investment to 
install, it may offer a pragmatic solution on farms for which in-parlor transmission appears to be a problem but for whom segregation is not a viable option.

The role of the milking machine in transmission of mastitis should not be ignored despite advancements aimed at reducing its involvement. It is considered to account for up to $20 \%$ of new IMI in some herds, although it is probably closer to around $10 \%$ in most average herds, provided the machine is appropriately configured (Mein, 2012). To minimize the risk of pathogen spread via the milking machine, it should be inspected at least annually (Dufour et al., 2011), which is especially pertinent given that $61 \%$ of UK parlors failed their annual test in one study (Berry et al., 2005).

The measuring and hence monitoring of transmission remains challenging at present and has typically been estimated using SCC trends, CM incidence data, and bacteriology (Barkema et al., 2009). Molecular epidemiological techniques (Zadoks and Schukken, 2006) are required to measure how much transmission is occurring and these are not currently widely available in the commercial setting. This is, however, likely to change with advances in technology and, thus, the ability to accurately quantify and monitor the degree of transmission in dairy herds should improve.

After transmission, the most important factors influencing the cost of $\mathrm{CM}$ were bacteriological cure rate, cost of a cull, and loss in yield. This is consistent with other studies (Huijps et al., 2008; Halasa, 2012; Heikkilä et al., 2012). van den Borne et al. (2010) also reported that the cost of mastitis was sensitive to the bacteriological cure rate, with higher cure rates resulting in reduced costs due to mastitis when modeling the effect of lactational treatment of subclinical IMI. Barlow et al. (2009) found that increasing the cure rate of subclinical IMI was beneficial at some levels of transmission but when transmission was high, it could be counterproductive, as it resulted in more uninfected cows (quarters) being available to be reinfected.

In the model used in this study, bacteriological cure rate was structured to be affected by cow factors such as parity, SCC at the time of infection, systemic illness, case number, and DIM, as described by Steeneveld et al. (2011). However, we used probability distributions rather than point estimates for the cow factors and this resulted in a highly variable set of possible values for bacteriological cure rate, which we believe reflects real potential situations. As expected, factors that affect the probability of bacteriological cure had an important influence on the cost of $\mathrm{CM}$, although more research would be useful to determine the real degree of variation in these values in the field and the reasons for such variation. The other parameters in the model, such as milk price, length of milk withdrawal, and the cost of labor, proved to be of lesser significance to the cost of CM. Interestingly, the cost of medicines was found to have little bearing on the overall cost of a case of CM (Table 3).

In this study, the probability distributions used for the bacteriological cure rate reflected an increased chance of cure for the more aggressive treatment protocols overall (Table 1). A large degree of overlap existed in the bacteriological cure rates for the different treatment protocols and the same was true of the model outputs (Table 4), which showed that the overall cost of CM was very similar despite the treatment protocol selected. The median total costs (Table 4) were higher than most figures quoted in the literature, as they included the costs incurred by any transmission that happened as a result of the case of CM, which most other figures do not. So, rather than representing the cost of a case of CM, it may be more appropriate to think of the values for total cost in Table 4 in terms of the room for investment in preventing a case of CM. The median costs, without taking into account transmission, were higher than the equivalent figures quoted by Steeneveld et al. (2011) but these do not necessarily represent an average cost for mastitis because with the use of uniform distributions in the current study, the aim was to fully explore causes of variation in cost rather than averages. Treatment 1 ( $3 \mathrm{~d}$ of intramammary antibiotic) resulted in the lowest median cost, as was found by Steeneveld et al. (2011), but also had the broadest range, which is intuitive, given the increased risk of transmission, subclinical infection, and culling associated with a reduced bacteriological cure rate. Therefore, and importantly, the treatment protocol selected appears to be much less important than other factors such as transmission. Steeneveld et al. (2011) hypothesized that the inclusion of transmission would favor the intensive antibiotic treatment regimens and some evidence existed to support this hypothesis in the results from our model, with the most aggressive treatment protocol (treatment 5 ) being less highly correlated to the rate of transmission than the other protocols (Table 3) and resulting in fewer cows becoming infected due to transmission (Table 4). The increased bacteriological cure rate associated with treatment 5 was based on expert opinion rather than specific studies, but if intensive antibiotic treatment protocols were indeed found to reduce transmission, then our model would indicate that the potential economic benefits could be far greater than simply those associated with the individual cow. More data on expected cure rates would be needed to improve our understanding of this aspect.

The use of modeling in economic evaluations is now widespread in the healthcare sector, as it enables the 
investigation of the likely range of outcomes (costeffectiveness) under different assumptions, even when the exact magnitude of key variables is unknown (Buxton et al., 1997). Probabilistic sensitivity analysis has become the state-of-the-art method for determining the uncertainty in the outcomes of cost-effectiveness studies because of the uncertainty in input parameters (Boshuizen and van Baal, 2009). Concerns exist that the use of deterministic or univariate sensitivity analysis may underestimate overall uncertainty (Briggs, 2000) and become difficult to interpret with large numbers of parameters, especially if any are correlated (Claxton et al., 2005). Such limitations with other forms of sensitivity analysis have led to the development of PSA based on Monte Carlo simulation methods (O'Brien et al., 1994). Probabilistic sensitivity analysis permits the analyst to examine the effect of joint uncertainty in the variables of an analysis without resorting to the wide range of results generated by extreme scenario analysis (Briggs and Gray, 1999). Parameter correlation is propagated automatically, providing meaningful sensitivity analysis, regardless of parameter correlation (Ades et al., 2006). Given that the literature is often quite sparse concerning many of the model inputs required, assumptions are usually necessary for this kind of model and this can result in unreliable conclusions being drawn if this uncertainty is not properly investigated. By using PSA, we can reflect the level of uncertainty by defining the parameters as distributions that are specified and transparent. The distributions used do require a degree of judgment and this has to be carried out in an open and transparent way and based on current literature where possible.

Our model calculated transmission over a limited period of $12 \mathrm{wk}$, a constraint primarily due to increasing model complexity. The amount of time that a cow remains infective following an IMI is dependent on many different factors and, hence, extremely variable. The duration of non-agalactiae streptococcal infections may range from $1 \mathrm{~d}$ to 1 lactation (Todhunter et al., 1995; Zadoks et al., 2003), with a median of $42 \mathrm{~d}$ (Zadoks et al., 2003). For Staph. aureus, the average length of infectivity was found to be $115 \mathrm{~d}$ for herds practicing postmilking teat disinfection (Lam et al., 1997). Given these findings, the 12-wk period that we used could have resulted in an underestimation of the effect of transmission.

\section{CONCLUSIONS}

The risk of transmission was found to be by far the most influential parameter in a PSA investigating the factors affecting the cost of $\mathrm{CM}$ at the individual cow level. This was followed by bacteriological cure rate, cost of culling, and loss of yield. The results from this study suggest that more emphasis should be placed on the reduction in the risk of transmission in dairy herds when seeking to minimize the economic impact of CM.

\section{REFERENCES}

Ades, A. E., K. Claxton, and M. Sculpher. 2006. Evidence synthesis, parameter correlation and probabilistic sensitivity analysis. Health Econ. 15:373-381.

Bar, D., L. W. Tauer, G. Bennett, R. N. González, J. A. Hertl, Y. H. Schukken, H. F. Schulte, F. L. Welcome, and Y. T. Gröhn. 2008. The cost of generic clinical mastitis in dairy cows as estimated by using dynamic programming. J. Dairy Sci. 91:2205-2214.

Barkema, H. W., M. J. Green, A. J. Bradley, and R. N. Zadoks. 2009. Invited review: The role of contagious disease in udder health. J. Dairy Sci. 92:4717-4729.

Barlow, J. W., L. J. White, R. N. Zadoks, and Y. H. Schukken. 2009. A mathematical model demonstrating indirect and overall effects of lactation therapy targeting subclinical mastitis in dairy herds. Prev. Vet. Med. 90:31-42.

Berry, E. A., M. Scrivens, and J. E. Hillerton. 2005. Milking machine test survey of UK herds. Vet. Rec. 157:147-148.

Boshuizen, H. C., and P. H. M. van Baal. 2009. Probabilistic sensitivity analysis: Be a Bayesian. Value Health 12:1210-1214.

Bradley, A. J. 2002. Bovine mastitis: An evolving disease. Vet. J. 164:116-128.

Briggs, A. H. 2000. Handling uncertainty in cost-effectiveness models. Pharmacoeconomics 17:479-500.

Briggs, A. H., R. Goeree, G. Blackhouse, and B. J. O'Brien. 2002. Probabilistic analysis of cost-effectiveness models: Choosing between treatment strategies for gastroesophageal reflux disease. Med. Decis. Making 22:290-308.

Briggs, A. H., and A. M. Gray. 1999. Handling uncertainty when performing economic evaluations of health care interventions: A systematic review with special reference to the variance and distributional form of cost data. Health Technol. Assess. 3.

Brown, J., N. J. Welton, C. Bankhead, S. H. Richards, L. Roberts, C. Tydeman, and T. J. Peters. 2006. A Bayesian approach to analysing the cost-effectiveness of two primary care interventions aimed at improving attendance for breast screening. Health Econ. $15: 435-445$.

Buxton, M. J., M. F. Drummond, B. A. Van Hout, R. L. Prince, T. A. Sheldon, T. Szucs, and M. Vray. 1997. Modelling in economic evaluation: An unavoidable fact of life. Health Econ. 6:217-227.

Claxton, K., M. Sculpher, C. McCabe, A. Briggs, R. Akehurst, M. Buxton, J. Brazier, and T. O'Hagan. 2005. Probabilistic sensitivity analysis for NICE technology assessment: Not an optional extra. Health Econ. 14:339-347.

DairyCo. 2012a. GB farmgate milk prices. Accessed Feb. 12, 2012. http://www.dairyco.org.uk/market-information/milk-pricescontracts/farmgate-prices/uk,-gb-and-ni-farmgate-prices/.

DairyCo. 2012b.GB cow and heifer prices. Accessed Feb. 12, 2012. http://www.dairyco.org.uk/market-information/farm-expenses/ cow-heifer-prices/gb-cow-heifer-prices/.

Detilleux, J. C. 2004. Javelin diagrams: Applications in veterinary medical decision analysis. Vet. Res. 35:617-624.

Dufour, S., A. Fréchette, H. W. Barkema, A. Mussell, and D. T. Scholl. 2011. Invited review: Effect of udder health management practices on herd somatic cell count. J. Dairy Sci. 94:563-579.

Fox, L. K., and J. M. Gay. 1993. Contagious mastitis. Vet. Clin. North Am. Food Anim. Pract. 9:475-487.

Hagnestam, C., U. Emanuelson, and B. Berglund. 2007. Yield losses associated with clinical mastitis occurring in different weeks of lactation. J. Dairy Sci. 90:2260-2270.

Hagnestam-Nielsen, C., and S. Østergaard. 2009. Economic impact of clinical mastitis in a dairy herd assessed by stochastic simulation using different methods to model yield losses. Animal 3:315-328. 
Halasa, T. 2012. Bioeconomic modeling of intervention against clinical mastitis caused by contagious pathogens. J. Dairy Sci. 95:57405749 .

Halasa, T., K. Huijps, O. Østerås, and H. Hogeveen. 2007. Economic effects of bovine mastitis and mastitis management: A review. Vet. Q. 29:18-31.

Halasa, T., M. Nielen, R. B. M. Huirne, and H. Hogeveen. 2009. Stochastic bio-economic model of bovine intramammary infection. Livest. Sci. 124:295-305.

Heikkilä, A.-M., J. I. Nousiainen, and S. Pyörälä. 2012. Costs of clinical mastitis with special reference to premature culling. J. Dairy Sci. 95:139-150.

Hogan, J. S., R. J. Harmon, B. E. Langlois, R. W. Hemken, and W. L. Crist. 1984. Efficacy of an iodine backflush for preventing new intramammary infections. J. Dairy Sci. 67:1850-1859.

Huijps, K., T. J. Lam, and H. Hogeveen. 2008. Costs of mastitis: Facts and perception. J. Dairy Res. 75:113-120.

Keefe, G. 2012. Update on control of Staphylococcus aureus and Streptococcus agalactiae for management of mastitis. Vet. Clin. North Am. Food Anim. Pract. 28:203-216.

Kossaibati, M. A., and R. J. Esslemont. 2000. The cost of clinical mastitis in UK dairy herds. Cattle Pract. 8:323-327.

Lam, T. J. G. M., M. C. M. Dejong, Y. H. Schukken, and A. Brand. 1996. Mathematical modeling to estimate efficacy of postmilking teat disinfection in split-udder trials of dairy cows. J. Dairy Sci. $79: 62-70$

Lam, T. J., J. H. van Vliet, Y. H. Schukken, F. J. Grommers, A. van Velden-Russcher, H. W. Barkema, and A. Brand. 1997. The effect of discontinuation of postmilking teat disinfection in low somatic cell count herds. II. Dynamics of intramammary infections. Vet. Q. 19:47-53.

Lunn, D. J., A. Thomas, N. Best, and D. Spiegelhalter. 2000. WinBUGS-A Bayesian modelling framework: Concepts, structure, and extensibility. Stat. Comput. 10:325-337.

Mein, G. A. 2012. The role of the milking machine in mastitis control. Vet. Clin. North Am. Food Anim. Pract. 28:307-320.

Middleton, J. R., L. K. Fox, and T. H. Smith. 2001. Management strategies to decrease the prevalence of mastitis caused by one strain of Staphylococcus aureus in a dairy herd. J. Am. Vet. Med. Assoc. 218:1615-1618.

O'Brien, B. J., M. F. Drummond, R. J. Labelle, and A. Willan. 1994 In search of power and significance: Issues in the design and analysis of stochastic cost-effectiveness studies in health care. Med. Care 32:150-163.

Olde Riekerink, R. G. M., H. W. Barkema, D. T. Scholl, D. E. Poole, and D. F. Kelton. 2010. Management practices associated with the bulk-milk prevalence of Staphylococcus aureus in Canadian dairy farms. Prev. Vet. Med. 97:20-28.

R Development Core Team. 2012. R: A Language and Environment for Statistical Computing. R Foundation for Statistical Computing, Vienna, Austria.
Rodrigues, A. C. O., D. Z. Caraviello, and P. L. Ruegg. 2005. Management of Wisconsin dairy herds enrolled in milk quality teams. J. Dairy Sci. 88:2660-2671.

Smith, T. W., R. J. Eberhart, S. B. Spencer, E. M. Kesler, G. L. Hargrove, R. W. Wilson, and C. W. Heald. 1985. Effect of automatic backflushing on number of new intramammary infections, bacteria on teatcup liners, and milk iodine. J. Dairy Sci. 68:424-432.

Steeneveld, W., T. van Werven, H. W. Barkema, and H. Hogeveen. 2011. Cow-specific treatment of clinical mastitis: An economic approach. J. Dairy Sci. 94:174-188.

Swinkels, J. M., H. Hogeveen, and R. N. Zadoks. 2005a. A partial budget model to estimate economic benefits of lactational treatment of subclinical Staphylococcus aureus mastitis. J. Dairy Sci 88:4273-4287.

Swinkels, J. M., J. G. Rooijendijk, R. N. Zadoks, and H. Hogeveen. 2005b. Use of partial budgeting to determine the economic benefits of antibiotic treatment of chronic subclinical mastitis caused by Streptococcus uberis or Streptococcus dysgalactiae. J. Dairy Res. 72:75-85.

Todhunter, D. A., K. L. Smith, and J. S. Hogan. 1995. Environmental streptococcal intramammary infections of the bovine mammary gland. J. Dairy Sci. 78:2366-2374.

van den Borne, B. H. P., T. Halasa, G. van Schaik, H. Hogeveen, and M. Nielen. 2010. Bioeconomic modeling of lactational antimicrobial treatment of new bovine subclinical intramammary infections caused by contagious pathogens. J. Dairy Sci. 93:4034-4044.

Wilson, D. J., R. N. Gonzalez, and P. M. Sears. 1995. Segregation or use of separate milking units for cows infected with Staphylococcus aureus: Effects on prevalence of infection and bulk tank somatic cell count. J. Dairy Sci. 78:2083-2085.

Zadoks, R. N., H. G. Allore, H. W. Barkema, O. C. Sampimon, Y T. Gröhn, and Y. H. Schukken. 2001. Analysis of an outbreak of Streptococcus uberis mastitis. J. Dairy Sci. 84:590-599.

Zadoks, R. N., H. G. Allore, T. J. Hagenaars, H. W. Barkema, and Y. H. Schukken. 2002. A mathematical model of Staphylococcus aureus control in dairy herds. Epidemiol. Infect. 129:397-416.

Zadoks, R. N., B. E. Gillespie, H. W. Barkema, O. C. Sampimon, S P. Oliver, and Y. H. Schukken. 2003. Clinical, epidemiological and molecular characteristics of Streptococcus uberis infections in dairy herds. Epidemiol. Infect. 130:335-349.

Zadoks, R. N., and Y. H. Schukken. 2006. Use of molecular epidemiology in veterinary practice. Vet. Clin. North Am. Food Anim. Pract. 22:229-261.

Zecconi, A., R. Piccinini, and L. K. Fox. 2003. Epidemiologic study of intramammary infections with Staphylococcus aureus during a control program in nine commercial dairy herds. J. Am. Vet. Med. Assoc. 223:684-688. 